\title{
Microstructural Behavior of the Intermetallic Compound CaMgSi Synthesized by Mechanical Milling and Spark Plasma Sintering
}

Jesus Luis Alberto Ponce-Ruiz ${ }^{1}$, Seya Ishizuka ${ }^{2}$, Nozomu Adachi ${ }^{2}$, Yuki Yamada ${ }^{2}$, Yoshikazu Todaka $^{2}$, Jose Ernesto Ledezma-Sillas ${ }^{1}$ and Jose Martin Herrera-Ramirez ${ }^{1}$

${ }^{1}$ Centro de Investicación en Materiales Avanzados, Chihuahua, Chihuahua, Mexico, ${ }^{2}$ Toyohashi University of Technology, Toyohashi, Aichi, Japan

Thermoelectricity is the phenomenon in which the waste heat can directly convert into electrical energy through the Seebeck effect. However, the use of thermoelectric materials has been limited because of their low efficiency and most of their uses toxic and/or expensive elements.

The intermetallic CaMgSi compound has a great potential for thermoelectric applications [1, 2]. Its ternary phase diagram was based on samples synthesized for the first time by arc melting [3]. New properties can be developed when nanostructured materials are obtained. For thermoelectric applications, there are two strategies for increasing the efficiency (figure of merit (ZT)): 1) introducing distortions in the lattice by nanoparticles or by decreasing the grain size in bulk materials and 2) adding doping elements to change the electronic properties. A novel method has been studied for the synthesis of thermoelectric materials, which combines mechanical milling (MM) and spark plasma sintering (SPS). The MM is used to homogenize stoichiometric compounds and to reduce the grain size, while SPS allows us to synthesize and consolidate the milled powders in a short period, limiting the grain growth $[4,5]$.

In this work, bulk CaMgSi samples were prepared combining MM and SPS. Elemental powders from Alfa Aaesar were used with the following specifications: $\mathrm{CaH}_{2} 99 \%, \mathrm{Mg}$ and $\mathrm{Si} 99.9 \%$ in purity with particle size of $200 \mu \mathrm{m}, 150 \mu \mathrm{m}$ and $5 \mu \mathrm{m}$, respectively. $\mathrm{CaH}_{2}$ was used instead of Ca because is more stable in air atmosphere. The powders were weighted inside a globe box filled with high purity argon gas. A planetary ball mill Pulverisette 5, with stainless steel (SUS304) vial and milling media, operated at 180 rpm was used to synthesize the compound for $20 \mathrm{~h}$. The ball-to-powder ratio was settled at $4: 1$. The milled powders were fixed in a graphite inside the glove box. For the sintering, a SPS (Dr Sinter SPS-1030, Sumitomo Coal Mining) machine was used under constant pressure of $50 \mathrm{MPa}$ at $1000{ }^{\circ} \mathrm{C}$. For this purpose, two cycles of $45 \mathrm{~min}$ with argon atmosphere and $25 \mathrm{~min}$ under vacuum were used. The resulting material was characterized by X-ray diffraction (XRD) using a PANalytical X'Pert Pro diffractometer and transmission electron microscopy using a JEOL JEM2200FS+CS microscope with an accelerating voltage of $200 \mathrm{kV}$.

Fig. 1 displays the XRD pattern of the processed material. The resulting phase corresponds to $\mathrm{CaMgSi}$, which matches with the JCPDS 01-089-1917. The sharpen peaks shows the high crystallinity of the material. Fig. 2 a show the TEM images pf the bulk sample processed by MM and SPS. The importance of obtaining nanoparticles is because they can reduce the mean free path of electrons (mfp). Furthermore, it allows to reduce the thermal conductivity of electrons increasing the thermoelectric properties [6]. The SAED in Fig. $2 b$ proves the high crystallinity reported in Fig. 1. The nanocrystalline CaMgSi compound was successfully synthesized by the combination of MM and SPS. Fig. 2c displays a TEM image that proves the presence of nanoparticles. 


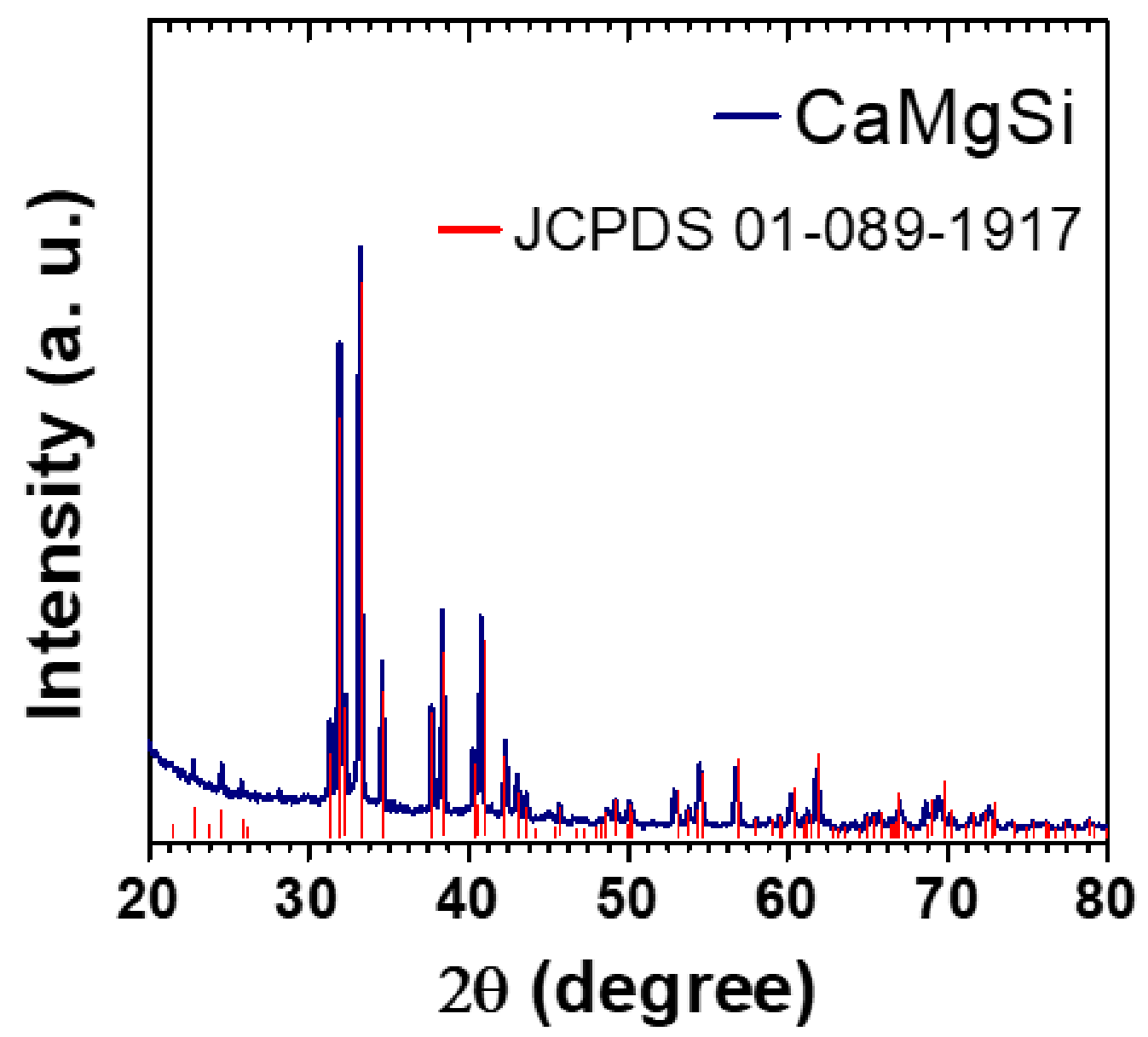

Figure 1. XRD pattern of the synthesized bulk $\mathrm{CaMgSi}$.
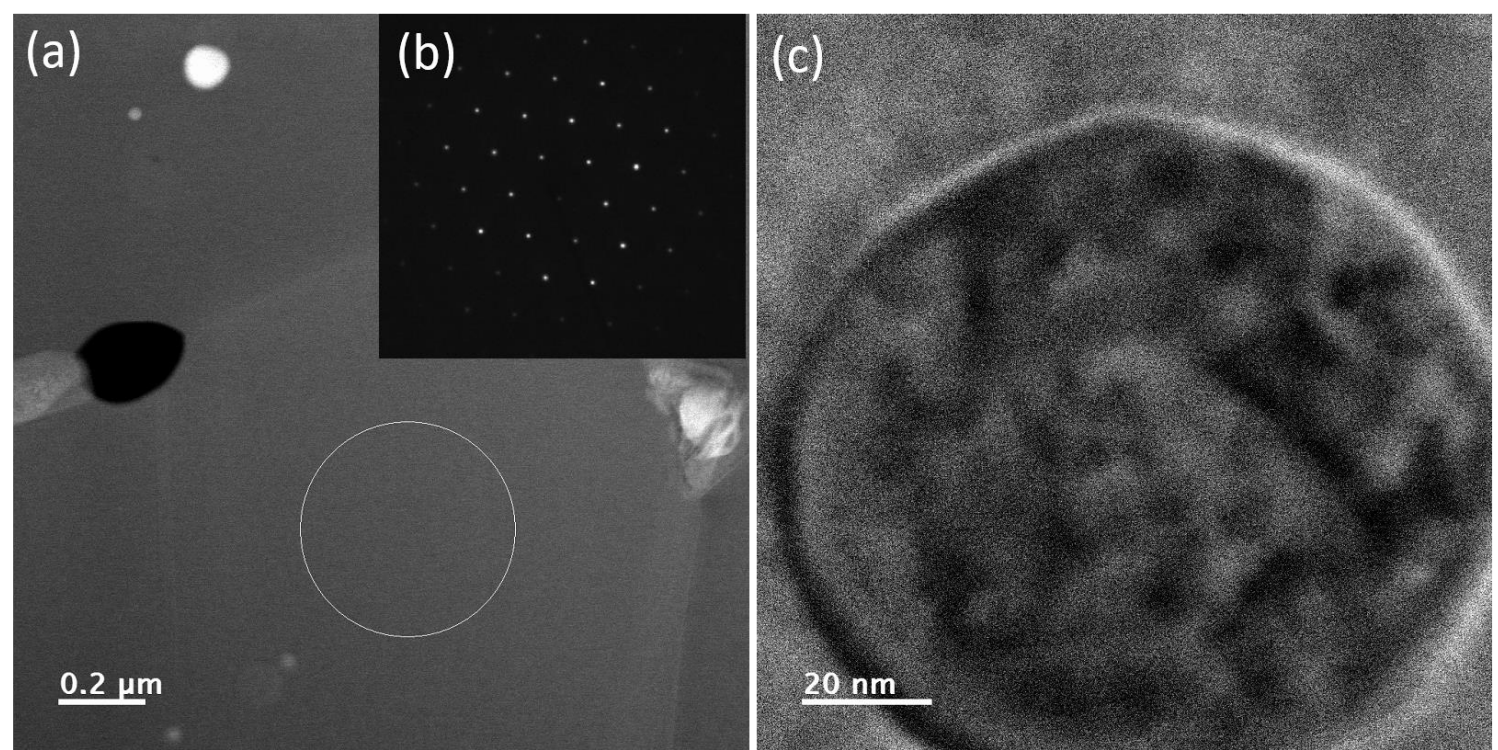

Figure 2. TEM images of synthesized bulk CaMgSi a) bright field image, b) SAED pattern and c) bright field image showing a nanoparticle. 


\section{References}

1. H. Miyazaki et al., "Electronic and crystal structures of thermoelectric CaMgSi intermetallic compound", J. Electron Spectros. Relat. Phenomena, 2016.

2. N. Miyazaki, N. Adachi, Y. Todaka, H. Miyazaki, y Y. Nishino, "Thermoelectric property of bulk CaMgSi intermetallic compound”, J. Alloys Compd., 2017.

3. J. Gröbner, I. Chumak, y R. Schmid-Fetzer, "Experimental study of ternary Ca-Mg-Si phase equilibria and thermodynamic assessment of $\mathrm{Ca}-\mathrm{Si}$ and $\mathrm{Ca}-\mathrm{Mg}-\mathrm{Si}$ systems", Intermetallics, vol. 11, núm. 10, pp. 1065-1074, 2003.

4. C. Suryanarayana, "Mechanical alloying and milling”, Mech. Alloy. Milling, núm. January 2007, pp. 1472, 2004.

5. P. Cavaliere, Spark Plasma Sintering of Materials. 2019.

6. X. Yan et al., "Enhanced thermoelectric figure of merit of p-type half-heuslers", Nano Lett., vol. 11, núm. 2, pp. 556-560, 2011. 